\title{
Virtual Technology Intervention
}

National Cancer Institute

\section{Source}

National Cancer Institute. Virtual Technology Intervention. NCI Thesaurus. Code C162917.

An intervention that makes use of software applications to create interactions that mimic human interactions. 